\title{
An Account of India's under-5 Mortality Rate
}

\author{
Rituparna Bhattacharyya
}

Alliance for Community Capacity Building in North East India, 57, Newington Drive, Preston Grange, North Shields NE29 9JA, UK

\begin{abstract}
Millennium Development Goal 4 (MDG4) of India targeted to diminish the under-five mortality rate (U-5MR) rate to 42 and infant mortality rate (IMR) to 27 per 1,000 live births by 2015 -end. Although the country has gained some improvements in reducing U-5MR and IMR, it failed to achieve the target. Despite, the Government of India's promises to strengthen the health system, it is merely a rhetoric. Lacunae and challenges remain. Improved financial commitments, alongside increased access to medical supplies, new technologies and regular interventions must be enhanced. This signals fortifying increased access to low-cost interventions and transnational support and health programs that can save lives.
\end{abstract}

Keywords Millennium Development Goal 4 (MDG4), Under-five Mortality Rate, Infant Mortality Rate, India

\section{Introduction}

India touts as one of the fast growing nations in the $21 \mathrm{st}$ Century - this much-vaunted achievement lies in the economic policies adopted in the late 1980s that led to escalation in its economic growth (Drèze and Sen, 2015). For a country with lower middle income - the Gross Domestic Product (GDP) rose from US\$189.6 billion in 1980 to US\$1.875 trillion in 2013. ${ }^{1}$ The Indian economy was estimated to grow at $7.5 \%$ in the fiscal year $2015-2016$. $^{2}$ However, its public health system and its overall health performing indices - to name a few, maternal and prenatal disorders, communicable disease, infant mortality and morbidity, and nutritional deficiencies - all continue to be one of the weakest in the world (Balarajan et al., 2011; Patel et al., 2011a, Rao et al., 2011; Shiv Kumar et al., 2011). This article reports on the state of India's under-five mortality rate (U-5MR). ${ }^{3}$ Between 1990 and 2015, India's Millennium Development Goal 4 (MDG4) aimed to reduce the U-5MR by two-thirds (Millennium Development Goals India Country Report, 2014), but the U-5MR report card is a matter of concern; it failed to achieve U-5MR to 42 and infant mortality rate (IMR) ${ }^{4}$ to 27 per 1,000 live births by 2015-end. The latest joint report by UN, UNICEF, World
Bank and WHO unveils that in 2013, the number of U-5MR in India stands at 1.3 million, which is $21 \%$ of all under-5 deaths - highest in the world. ${ }^{5}$ This report further reveals that of all the world's neonatal deaths, India accounts for more than 25\%. Apparently, another report published by Organisation for Economic Co-operation and Development (OECD) countries claims that IMR in India is ten times higher than the average 4.0 deaths per 1000 births in the OECD countries. ${ }^{6}$

Central to reducing U-5MR and IMR heavily depends upon the reduction of neonatal, post-neonatal, peri-natal deaths at a faster pace. Several interlaced factorsmultidimensional poverty, lack of electricity, unclean drinking water, unsafe homes, poor sanitation apace with malnutrition, mother's poor health, inadequate medical care (due to negligence, poor focus on prevention and meagre investment in public health) —all contribute directly or indirectly to U-5MR and IMR. Besides, a number of underlying factors deter a child's health. This is because the first few months remain crucial for a newborn. First, though, it is important to shed light on the quality of life of the majority of Indians, which bear profound implications on the overall health of the masses and on children in particular.

\section{Overall Scenario of India}

Scattered over 28 states/7 union territories including 640 districts, 497 cities, 5767 tehsils and over 6 hundred thousand villages, India is a home to 1.21 billion (623 million males and 587 million females) (Census of India, 2011). 377.1 million and 833.5 million persons live in urban and rural areas respectively, indicating that vast majority of Indians live in rural areas. The literacy rate is $73 \%(80.9 \%$ males and $64.6 \%$ females are literates). Out of this total population, $13.6 \%$ belong to the $0-6$ years ${ }^{7}$ group accounting 164.5 million ( 85.7 million boys and 78.7 million girls) (Census of India, 2011). Notwithstanding, the new Rangarajan poverty method ${ }^{8}$ unfolds that $29.5 \%(30.9 \%$ rural and $26.4 \%$ ) are mired in poverty implying that 363 million Indians are very poor (260.5 million rural and 102.5 million urban). It is evident that out of 246,692, 667 Census households (167,826, 720 rural and 78,865,937 urban),

ISSN: 2332-6840 (Online) 2332-6832 (Print) Copyright (C) 2016 by authors, all rights reserved. Authors agree that this article remains permanently open access under the terms of the Creative Commons Attribution License 4.0 International License 
$102,470,426$ are livable $(79,855,814$ rural and 22,614,612 urban), 131,019,820 (77,041,343 rural 53,978, 477 urban) are good, while 13,202,421 (10,929,573 rural and 2,272,848 urban) are in dilapidated conditions. Besides, 131,771,842 (10, 907, 1865 rural and 226, 999, 77 urban) households do not enjoy running water in their own premises (Census of India, 2011; also Bhattacharyya, 2015). Moreover, $77,545,034$ (72,435,303 rural and 5,109,731 urban) households use kerosene as the key source of lighting, and $1,164,584$ (897,760 rural and 266,824 urban) households continue to remain in dark with no lighting facilities (Census of India, 2011). A staggering 53.1\% and $41.6 \%$ respectively defecate and bath in open spaces (Census of India, 2011; Drèze and Sen, 2015; also Bhattacharyya, 2014). Devoid of these basic facilities, they remain disconnected from the increasingly globalized (Bhattacharyya, 2015) world but these dismal facilities reciprocate the substandard qualities of everyday lives that bear vulnerable implications on health.

The new Government headed by honourable Prime Minister, Mr. Narendra Damodar Modi mandates development and human welfare and promises to deliver the basic needs for every household by 2022 (Bhattacharyya, 2014). The social fabric of India across each individual state is complex, diverse and myriad. Ostensibly, many regions continue to practice child marriage and polygamy that contribute to high birth rates. This in turn affects the local and nuanced health issues (including U-5MR and IMR) differently. It is also worth noting that natural and human-made disasters -regular floods and conflicts especially in the poor and remote states not only causes displacement but also obliterate many development gains made previously. Given these complexities, extra dimensions must be taken as priorities to save under- 5 and infant deaths. The next section discusses the state of U-5MR and IMR.

\section{Report Card on U-5MR and IMR}

Notwithstanding, India has made substantial progress in reducing U-5MR and IMR (Figures 1 and 2). The launch of National Rural Health Mission (NRHM) in 2005, now renamed as National Health Mission (NHM), has strengthened the public health system (PHY) (Patel et al., 2011); the recruitment of 900,000 Accredited Social Health Activists (ASHA) in remote areas, 178,000 health workers and 18,000 ambulances for emergency and free patient transport services have definitely taken the PHY to the rural mass. ${ }^{9}$ Alongside, the Reproductive and Child Health Programs - Janani Suraksha Yojna (JSY) and Janani Shishu Suraksha Karyakram (JSSK) aimed at tackling IMR, Maternal Mortality Rate (MMR) and Total Fertility Rate (TFR) have shown positive signs. For instance, the introduction of Mother and Child Tracking System (MCTS) have improved the care facilities for pre-natal, institutional delivery, and post-natal, with child immunization facilities. Currently, 20.8 million pregnant women and 16.7 million children are the beneficiaries of JSY and JSSK, which remain totally free at the point of care - no-fee even for caesarean cases, drugs, diagnostics, blood and diet including free transport services. Institutional deliveries conducted by trained or ASHA workers have also increased. In 2013-14, the number of institutional deliveries stands at 8.09 million carried out by 10.6 million trained health workers, which ascended from 0.738 million in 2005-06. ${ }^{9}$

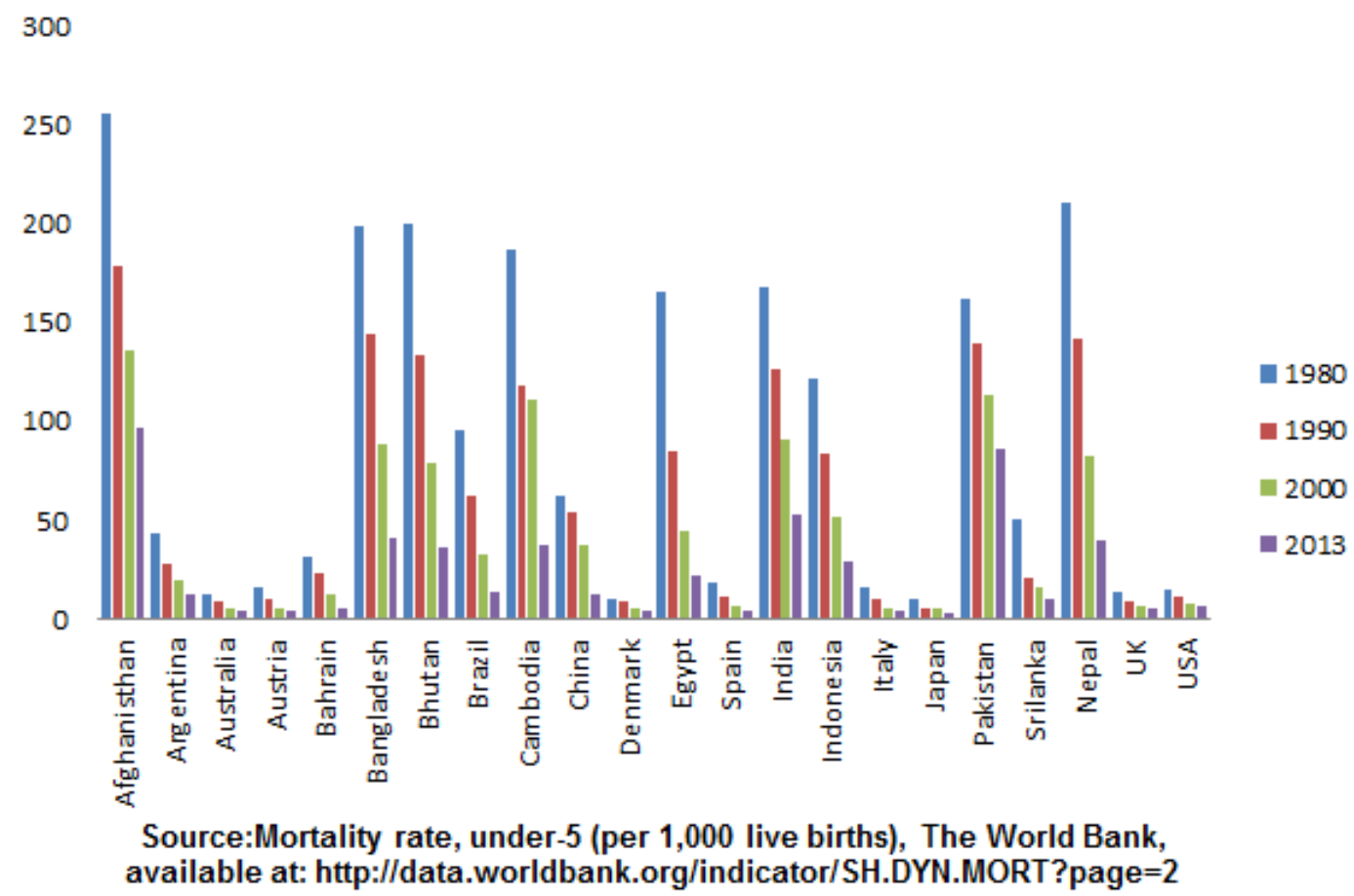

Figure 1. Trend Showing Under-5 Mortality of Few Countries 


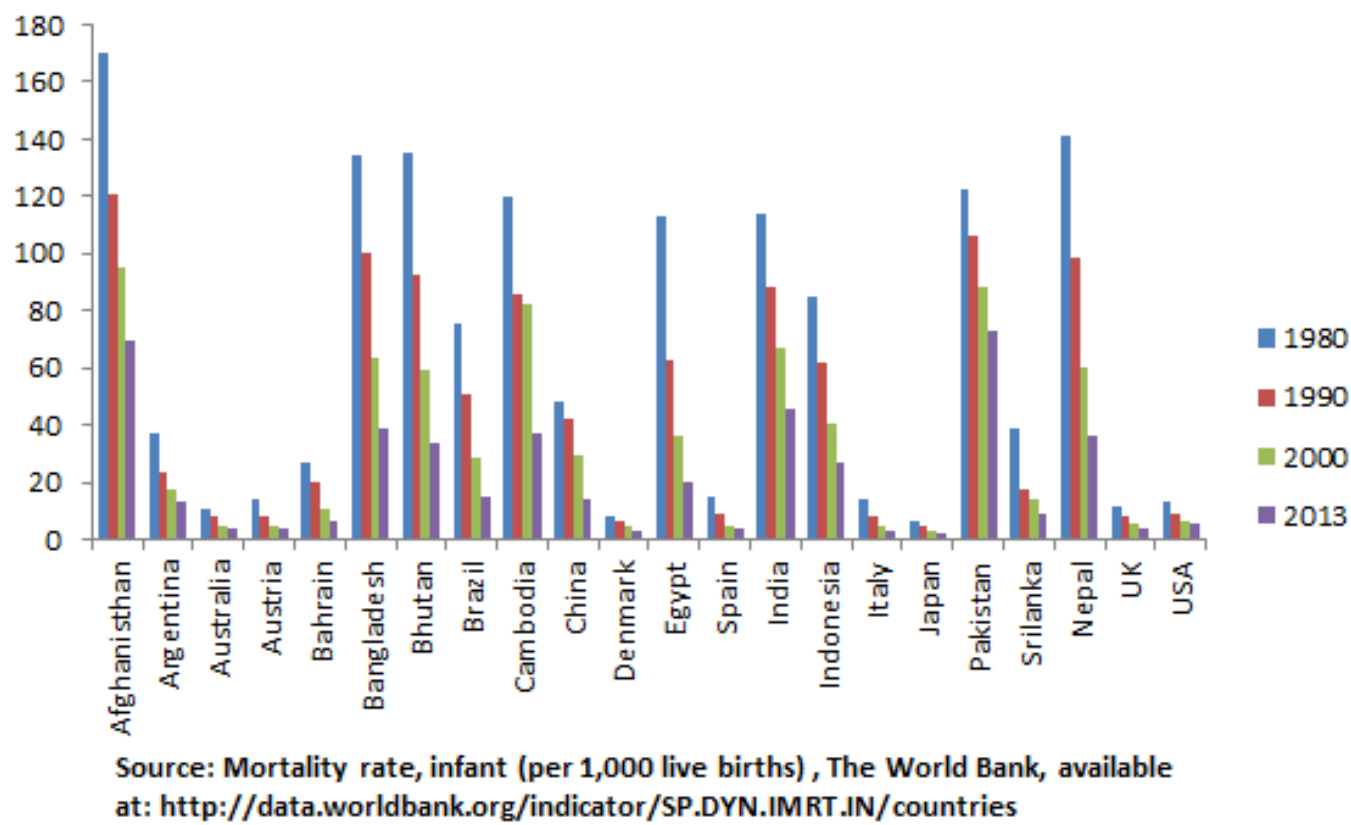

Figure 2. Trend Showing Infant Mortality Rate of Few Countries

However, the hard reality is that despite India's achievements in reducing U-5MR, its neo-natal death is almost $56 \%$ of its Under-5 deaths. Approximately 7,48,000 babies die within the first 28 days. This signals that almost 2000 newborns die across the country each day, which is quite high when compared to the global average fall of $44 \%$. Evidently, India achieved 59\% reduction in Under-5 deaths that accounted 126 in 1990 to 53 in 2013 (Figure 1), while the global decline stands at $49 \%$, which plummeted from 90 in 1990 to 46 in 2013. Seemingly, it can be seen from the data in Figures 1, 2, and Table 1 that U-5MR, IMR and even MMR of poorer South Asian countries have performed better than India. For examples, U-5MR and IMR of Bhutan, Bangladesh, Sri Lanka and even Nepal ${ }^{10}$ are better than India (Figures 1 and 2). Similarly, the MMR for Bhutan, Bangladesh, Pakistan and Sri Lanka are respectively 120, 170, 170 and 29; it is 190 for India (Table 1). These observations bear resonance to the findings of Drèze and Sen (2015). Despite considerable attention on health in the 2014 general election (Sachan, 2014), the public health expenditure remains meagre accounting for only $1 \%$ of its GDP in the 2015-2016 Union Budget (Table 1), one of the lowest in the world for a population of more than 1.21 billion (Shiv Kumar et al., 2011). In terms of revenue and expenditure, the 2015-16 budget allocates INR 331.52 billion ( $\$ 5.22$ billion) on the healthcare sector, a slash of $11 \%$ from INR392.38 billion ( $\$ 6.17$ billion) in the financial year 2014-2015. Not to speak of the developed nations - the USA, the UK, Australia, Spain, Denmark, Italy, Japan, the healthcare expenditure of India is even lower than many developing countries-Afghanistan, Bhutan, Bangladesh, Cambodia, Pakistan, Sri Lanka and Nepal (Table 1). The spending cuts on healthcare severely affects the NHM and its ASHA support services, albeit the increased allocation on
Integrated Child Development Scheme (ICDS) by INR 15 billion ( $\$ 0.23$ billion) and Integrated Child Protection Scheme (ICPS) by INR 5 billion ( $\$ 0.079$ billion) are anticipated to improve nutrition and other services to pregnant and lactating mothers and infants. In addition, the new budget 2015-16 also, promises to build 60 million toilets under Mr. Modi's initiative Clean India or Swachh Bharat Abhiyan launched on 02 October 2014, thereby, aims to improve the quality of life and healthcare standards. ${ }^{11}$

Though India gains success in defeating polio in 2014, the magnitude of malnourished children looms large and emerges as a silent killer. The Unicef India reports that one in three malnourished children of the world lives in India. ${ }^{12}$ WHO unfolds that in 2013, the key causes of deaths in Indian children under-5 (Figure 3) were prematurity (27\%), acute respiratory infections $(13 \%)$, birth asphyxia $(11 \%)$, diarrhea $(10 \%)$, neonatal sepsis $(8 \%)$, congenital anomalies $(7 \%)$, injuries $(4 \%)$, measles $(1 \%)$ and other diseases $(15 \%)$. In 2013 , approximately $84 \%$ children from different parts of the globe were vaccinated against diphtheria, tetanus and pertussis (DTP) and measles, in India, this coverage was close to $75 \%$.

The Unicef India further reveals that $46 \%$ of children suffer from growth disorder (stunting, height for age), 47\% are underweight and $16 \%$ wasted (weight for height). The proportion of these children is generally higher in families suffering from the vagaries of poverty squalor, although genetic factor could play its part. ${ }^{6,12}$ Insufficient breast-feeding is one of the key concerns of malnutrition. This is because vast numbers of new mothers working in the informal economy with no provisions for 'maternity leave' or 'maternity benefits' are impelled to go back to work hardly after the delivery, leaving behind the newborns deprived of adequate nourishment and care. 
Vol.4. No.4 September, 2016, pp. 82-88

Table 1. Comparison of Gross National income (per capita), Total Expenditure on Health (per capita), Population Below Poverty Line and Maternal Mortality Rate of Few Countries of the World

\begin{tabular}{|c|c|c|c|c|c|c|}
\hline Countries & $\begin{array}{c}\text { Total } \\
\text { Population } \\
\text { (2014) } \\
\text { (in million) } \\
\end{array}$ & $\begin{array}{c}\text { Gross National } \\
\text { Income per capita } \\
\text { (PPP international \$, } \\
\text { 2012) }\end{array}$ & $\begin{array}{c}\text { Total Expenditure } \\
\text { on Health per capita } \\
\text { (Intl \$, 2012) }\end{array}$ & $\begin{array}{l}\text { Total Expenditure } \\
\text { on Health as \% of } \\
\text { GDP }(2012)\end{array}$ & $\begin{array}{l}\text { Population Below } \\
\text { Poverty Line (in \%) }\end{array}$ & $\begin{array}{c}\text { Maternal } \\
\text { Mortality Rate } \\
\text { (2013) }\end{array}$ \\
\hline Afghanisthan & 29.83 & 1,560 & 47 & 8.7 & 36 in $2008-2009$ & 400 \\
\hline Argentina & 41.0 & 11,730 & 1,551 & 8.5 & 30 in 2010 & 69 \\
\hline Australia & 23.0 & 43,300 & 4,068 & 9.1 & NA & 6 \\
\hline Austria & 8.4 & 43,390 & 5,065 & 11.5 & 6.2 in 2012 & 4 \\
\hline Bahrain & 1.3 & 18,910 & 971 & 3.9 & NA & 22 \\
\hline Bangladesh & 160 & 2,030 & 68 & 3.6 & 31.5 in $2014^{* *}$ & 170 \\
\hline Bhutan & 0.8 & 6,200 & 253 & 3.8 & 12 in 2012 & 120 \\
\hline Brazil & 199.24 & 11,530 & 1,109 & 9.3 & 21.4 in 2009 & 69 \\
\hline Cambodia & 14.8 & 2,330 & 135 & 5.4 & 20 in 2012 & 170 \\
\hline China & 1,390 & 9,040 & 480 & 5.4 & 6.1 in $2013^{*}$ & 32 \\
\hline Denmark & 5.59 & 43,430 & 4,720 & 11.2 & 13.4 in 2011 & 5 \\
\hline Egypt & 86.8 & 6,450 & 323 & 5 & 22 in 2008 & 45 \\
\hline Spain & 46.76 & 31,670 & 3,145 & 9.6 & 21.1 in 2012 & 4 \\
\hline India & 1,240 & 3,910 & 157 & 4.1 but reduced to $1^{I}$ & 29.5 in $2014^{\mathrm{I}}$ & 190 \\
\hline Indonesia & 247 & 4,730 & 150 & 3 & 11.7 in 2012 & 190 \\
\hline Italy & 60.89 & 32,920 & 3,040 & 9.2 & 29.9 in 2012 & 4 \\
\hline Japan & 127.6 & 36,300 & 3,578 & 10.1 & 16 in 2010 & 6 \\
\hline Pakistan & 180 & 2,880 & 77 & 2.7 & 22.3 in $2005-2006$ & 170 \\
\hline Srilanka & 21.09 & 6,030 & 189 & 3.2 & 8.9 in 2010 & 29 \\
\hline Nepal & 27.47 & 1,470 & 80 & 5.5 & 25.2 in 2011 & 190 \\
\hline UK & 62.78 & 37,340 & 3,495 & 9.4 & 16.2 in 2011 & 8 \\
\hline USA & 318 & 52,610 & 8,895 & 17.9 & 15.1 in 2010 & 28 \\
\hline
\end{tabular}

Source: The World Fact Book, Central Intelligence Agency, Note: "National estimates of the percentage of the population falling below the poverty line are based on surveys of sub-groups, with the results weighted by the number of people in each group. Definitions of poverty vary considerably among nations. For example, rich nations generally employ more generous standards of poverty than poor nations"

(https://www.cia.gov/library/publications/the-world-factbook/fields/2046.html); WHO **Ministry of Finance, Bangladesh, 2014; *in 2011, China set a new poverty line at RMB 2300 (approximately US \$3,630)(2013); 'i As per Rangarajan Method; ' in the 2015-2016 Union Budget. 


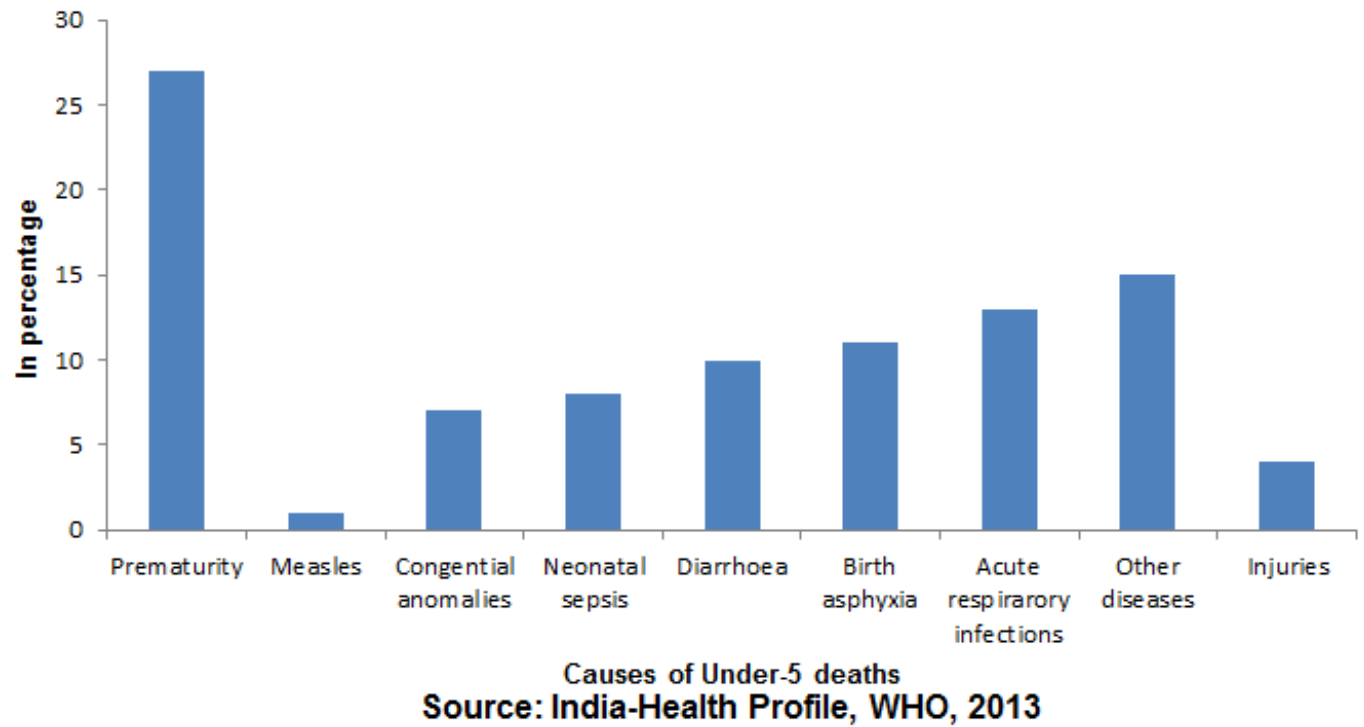

Figure 3. Caused of Under-5 death, India, 2013

Table 2. Under Five and Infant Mortality Rates, 2012

\begin{tabular}{|c|c|c|c|c|c|c|c|c|c|c|}
\hline \multirow{2}{*}{ States } & \multicolumn{5}{|c|}{ Under Five Mortality Rate } & \multicolumn{5}{|c|}{ Infant Mortality Rate } \\
\hline & Total & Boys & Girls & Rural & Urban & Total & Boys & Girls & Rural & Urban \\
\hline Assam & 75 & 71 & 80 & 80 & 37 & 55 & 54 & 57 & 58 & 33 \\
\hline Madhya Pradesh & 73 & 69 & 78 & 79 & 46 & 56 & 54 & 59 & 60 & 37 \\
\hline Uttar Pradesh & 68 & 62 & 75 & 72 & 49 & 53 & 52 & 55 & 56 & 39 \\
\hline Orissa & 68 & 67 & 70 & 72 & 42 & 53 & 52 & 54 & 55 & 39 \\
\hline Rajasthan & 59 & 52 & 67 & 65 & 36 & 49 & 47 & 51 & 54 & 31 \\
\hline Bihar & 57 & 54 & 60 & 58 & 39 & 43 & 42 & 45 & 44 & 34 \\
\hline Chattisgarh & 55 & 48 & 62 & 57 & 40 & 47 & 46 & 47 & 48 & 39 \\
\hline Jharkhand & 50 & 47 & 54 & 53 & 31 & 38 & 36 & 39 & 39 & 27 \\
\hline Haryana & 48 & 45 & 52 & 52 & 39 & 42 & 41 & 44 & 46 & 33 \\
\hline Gujarat & 48 & 46 & 50 & 56 & 32 & 38 & 36 & 39 & 45 & 24 \\
\hline Jammu and Kashmir & 43 & 40 & 46 & 43 & 37 & 39 & 38 & 40 & 41 & 28 \\
\hline Himachal Pradesh & 43 & 40 & 46 & 43 & 37 & NA & NA & NA & NA & NA \\
\hline Andhra Pradesh & 43 & 40 & 46 & 48 & 31 & 41 & 40 & 43 & 46 & 30 \\
\hline West Bengal & 38 & 37 & 39 & 40 & 29 & 32 & 31 & 33 & 33 & 26 \\
\hline Karnataka & 37 & 35 & 39 & 40 & 31 & 32 & 30 & 34 & 36 & 24 \\
\hline Punjab & 34 & 29 & 40 & 38 & 26 & 28 & 27 & 29 & 30 & 24 \\
\hline Maharashtra & 28 & 27 & 28 & 33 & 20 & 25 & 24 & 26 & 30 & 17 \\
\hline Delhi & 28 & 27 & 30 & 39 & 26 & 25 & 24 & 26 & 36 & 23 \\
\hline Tamil Nadu & 24 & 23 & 26 & 28 & 20 & 21 & 21 & 22 & 24 & 18 \\
\hline Kerala & 13 & 12 & 14 & 13 & 10 & 12 & 10 & 13 & 13 & 9 \\
\hline India & 52 & 49 & 56 & 58 & 32 & 42 & 41 & 44 & 46 & 28 \\
\hline \multicolumn{11}{|c|}{ Source: Millennium Development Goals, India Country Report 2014} \\
\hline
\end{tabular}

Clearly, there are massive incongruity between the states with respect to reducing U-5MR and IMR. The states: Kerala, Tamil Nadu, Delhi and Maharashtra have already achieved both MDG4 targets of U-5MR and IMR (Table 2), while the states of Punjab, Karnataka, West Bengal, Andhra Pradesh, Himachal Pradesh and Jammu and Kashmir have achieved the national target of U-5MR and are likely to achieve IMR along with Gujarat, Haryana and Jharkhand by the 2015-end.
With 75 per 1000 live births, Assam occupies the first position in its inability to meet MDG4 national target of U-5MR and IMR. Madhya Pradesh, Uttar Pradesh, Orissa, Rajasthan, Bihar and Chhattisgarh follow Assam. Because of subordinate social position, girls, especially from rural areas are at higher risk of U-5MR and IMR than the boys are. At all-India level, U5MR for girls is 56 and for boys is 49 . This gap in U-5MR is higher in rural areas (62:54) when 
compared to urban areas (34:31). Similarly, in the case of IMR too, there is a gap between girls and boys (at national level, IMR for girls' stands at 44, while for boys' it is 41). There is an 18-point rural-urban IMR gap (rural-46, urban 28).

This calls for serious introspection for states performing poorly. Interventions made by NHM are impressivelaunch of mobile health units, boat clinics, helicopter services to reach the distant places, but are yet to make a difference in the poorly performed states (Patel et al., 2011; Satia et al., 2014; Sarma and Bhattacharyya, 2015). Although NHM has recruited doctors through cash incentives in faraway areas (Satia et al., 2014; Sarma and Bhattacharyya, 2015); without supply of medicines, obsolete medical equipment and shortage of trained health and paramedical staff (Rao et al., 2011), the purpose remains unserved. OECD Health Statistics 2014 report seemingly unveils that in 2012, India had only 1.1 nurses and 0.7 physicians per 1000 population. However, there is a risk of these statistics being exaggerated as the OECD Health report claims. This is because the country fails to keep an up-to-date record of the medical registers in order to appropriately track for migration, retirement or death, and even on doctors registered in multiple states.

\section{Way Forward}

Every child has a right to a healthy life. Recognizing this, while the National Policy for Children, 2013 commits redress; the draft National Health Policy, $2015^{13}$ proposes health as a fundamental right that ensures universal access to free drugs, diagnostics in government hospitals, denials of which are criminal offences. However, there remains disconnect between promises and reality. As discussed above, the public health expenditure remains dismal. On one hand, Mr. Modi promises to build a prosperous young India through his initiatives, Make in India (25 September 2014) and Swachh Bharat Abhiyan. On the other hand, its MDG4 performance is poor. It is worth noting here that the youth population of the country is expected to reach 464 million in 2021 and 458 million in 2026 (Shivkumar, 2013). A healthy young India is only possible when its foundation is built in strongly. A conscientious and integrated endeavor among the front-line functionaries addressing child welfare alongside increased financial and human resource investment in health infrastructure and lifting people out of multi-dimensional poverty remains paramount to tackle the challenges that lie ahead. For this, pertinent low-cost interventions through new technologies in parallel to increased and easy access to medical supplies requires enhancement. In addition, transnational child survival support and health programs must be adopted ensuring that treatment is available for children suffering from any killer diseases.

\section{Endnotes}

1. Data-India: South Asia, World Bank, available at: http://data.worldbank.org/country/india (accessed 23 April 2015).

2. GDP growth rate: India to outpace China this year, Times of India (2015 February 9).

3. The World Bank defines U-5MR as "the probability per 1,000 that a newborn baby will die before reaching age five, if subject to age-specific mortality rates of the specified year".

4. As per the definition of the World Bank, IMR is the number of infants dying before reaching one year of age, per 1,000 live births in a given year.

5. Levels \& Trends in Child Mortality, Report 2014, Estimates Developed by the UN Inter-agency Group for Child Mortality Estimation, available at: http://www.data.unicef.org/fckimages/uploads/141086 9227_Child_Mortality_Report_2014.pdf (accessed 02 January 2015).

6. OECD Health Statistics 2014: How does India compare?, OECD, available at: http://www.oecd.org/els/health-systems/Briefing-Note -INDIA-2014.pdf (accessed 20 April 2015).

7. Data for 0-5 years in not available.

8. This method adopts a 'multi-dimensional' approach based on certain minimum consumption expenditure per person or preferably per household on food (accounting nutritional standards), education and health. The report finds that three out of every 10 people in India are poor. The Committee has drawn a poverty limit - those spending less than INR 47 per day in urban areas and INR 32 per day in rural areas are considered as poor. This method dismissed the earlier Suresh Tendulkar methodology that estimated the poverty ratio at 21.9 (269.8 million) in 2011-2012. As per Rangarajan method, there has been an increase of $35 \%$ of the population living below the poverty line (Report of the Expert Group to Review the Methodology for Measurement of Poverty, Government of India, Planning Commission, June 2014).

9. Chapter 13, Human Development, Economic Survey, 2013-14, available at:http://indiabudget.nic.in/es201314/echap-13.pdf (accessed 15 January 2015).

10. However, the picture of Nepal might be different after the devastated Nepal Earthquake that occurred on 25 April 2015 and the subsequent collapsing of buildings that killed more than 6300 people and seriously injured many, triggering thereby a poverty crisis.

11. Union Budget, 2015-16, Union Budget of India, available at: http://indiabudget.nic.in/budget.asp (accessed 01 May 2015).

12. Nutrition, India, UNICEF, available at: http://www.unicef.org/india/children_2356.htm (accessed 05 January 2015). 
13. National Health Policy 2015 Draft, Ministry of Health and Family Welfare, Government of India.

\section{REFERENCES}

Balarajan,Y., Selvaraj, S. and Subramanian, S.V. (2011). Health care and equity in India, The Lancet, 377 (9764), 505-511.

Bhattacharyya, R (2015). Dyson, Jane. 2014: Working Childhoods: Youth, agency and the environment in India. Cambridge, United Kingdom: Cambridge University Press. 186 pp. $£ 50.00$ hardback. ISBN: 9781107058385, Progress in Development Studies, 15(3), 292-294, DOI: $10.1177 / 1464993415578570$

Bhattacharyya, R. (2014). Good Governance and Development Mandate, Journal Space and Culture, India, 2(1), 1-4, DOI: 10.20896/saci.v2i1.65

Census info India 2011, Census of India, available at: http://www.devinfolive.info/censusinfodashboard/ (accessed 24 December 2014).

Drèze, J. and Sen, A. (2015). An Uncertain Glory: India and its Contradictions, New Jersey: Princeton University Press.

Millennium Development Goals India Country Report 2014, available at: http://www.indiaenvironmentportal.org.in/content/38 7190/millennium-development-goals-india-country-report-2014/ (accessed 24 December 2014).
Patel, V., Shiva Kumar, A.K., Paul, V.K., Rao, K.D. and Reddy, K.S. (2011). Universal health care in India: the time is right, The Lancet, 377(9764), 448 - 449.

Rao, M., Rao, K. D., Shiva Kumar, A.K., Chatterjee, Sundararaman, T. (2011). Human resources for health in India, The Lancet, 377(9765), 587-598.

Sachan, D. (2014). Health gets greater attention in the 2014 Indian elections, The Lancet, 383(9925), 1281-1282.

Satia J., Misra, M., Arora, R. and Neogi, S. (2014). Innovations in Maternal Health: Case Studies from India, New Delhi: Sage Publications.

Sarma, J.B. and Bhattacharyya, R. (2015). Half Empty or half filled? Notes on Universal Health Coverage in Northeast India, The Clarion, 4 (1), 154-184.

Shivakumar, G. (2013 April 17). India is set to become the youngest country 2020, The Hindu, available at:

http://www.thehindu.com/news/national/india-is-set-to-become-th e-youngest-country-by-2020/article4624347.ece (accessed 21 November 2014).

Shiva Kumar, A. K., Chen, L.C., Choudhury, M., Ganju, S., Mahajan, V., Sinha, A. and Sen. A. (2011). Financing health care for all: challenges and opportunities, The Lancet, 377(9766), 668 679. 